\title{
Evaluation of isolated DC/DC converter topologies for future HVDC aerospace microgrids
}

\author{
Luca Tarisciotti*, Alessandro Costabeber, Chen Linglin, Adam Walker, Mikiel Galea \\ Department of Electrical and Electronics Engineering \\ University of Nottingham \\ Nottingham, UK \\ *ezzlt@nottingham.ac.uk
}

\begin{abstract}
High performance power conversion equipment is currently gaining an increasing interest for aircraft applications. In particular, isolated bidirectional $\mathrm{DC} / \mathrm{DC}$ converters are often proposed for modern HVDC aircraft distribution systems. For such reason an evaluation of several isolated DC/DC converter topology is carried out considering the proposed application, interfacing a $270 \mathrm{~V}$ DC network with a $28 \mathrm{~V}$ DC network. A trade off evaluation has been carried out for three different topologies and an experimental prototype has been manufactured for the selected conversion architecture. Simulation and experimental results are provided in order to validate the trade off and the design of the proposed converter.
\end{abstract}

Keywords-DC/DC power conversion, Power Electronics, Dual Active Bridge, Active Clamp Active Bridge, More Electric Aircraft

\section{INTRODUCTION}

In recent years, the More Electric Aircraft (MEA) concept has gained an increased importance [1], [2]. In fact, electrical systems are replacing hydraulic, mechanical, or pneumatic power sources in a wide range of aerospace applications [3]-[5]. This increase in electrical energy demand has led to a rapid technology development, particularly in power electronics [6][8]. Electrical systems are now considered for aircraft actuation systems, wing ice protection systems, environmental control systems, and fuel pumping. These novel electrical systems aim to increase future aircraft efficiency, thus reducing the environmental impact of such systems and their maintenance cost. However, due to the electrical system complexity, future aircraft will face similar issues to the one found in ground based microgrids [1]-[5].

In such scenario, several structures for future aerospace microgrids have been proposed. Both $\mathrm{AC}$ and $\mathrm{DC}$ grids are investigated showing a trend in increasing the voltage level in such grids [9], [10]. Focusing on High Voltage Direct Current (HVDC) aerospace microgrids, Fig. 1 shows a typical grid structure which comprises a Low Voltage Direct Current (LVDC) network and a HVDC network. On the LVDC network typically Low Voltage (LV) emergency batteries and other energy storage elements, such as Electro-Mechanical Batteries (EMB) are connected together with the Electrical Power Unit (EPU) which supplies avionics circuitry [11]-[13]. On the HVDC network, High Voltage (HV) generators [14]-[18] provide the required voltage and power, together with $\mathrm{HV}$ batteries [11], [12] and other EPU [19], [20], which supplies electric actuators, de-icing systems and other MEA equipment [5], [21]-[23]. Moreover, Starter Generator (SG) systems [6], [24]-[28], together with their Electrical Control Unit (ECU) are able to provide the required power to start the aircraft engines, and generate additional power during flight, on the HVDC or LVDC network.

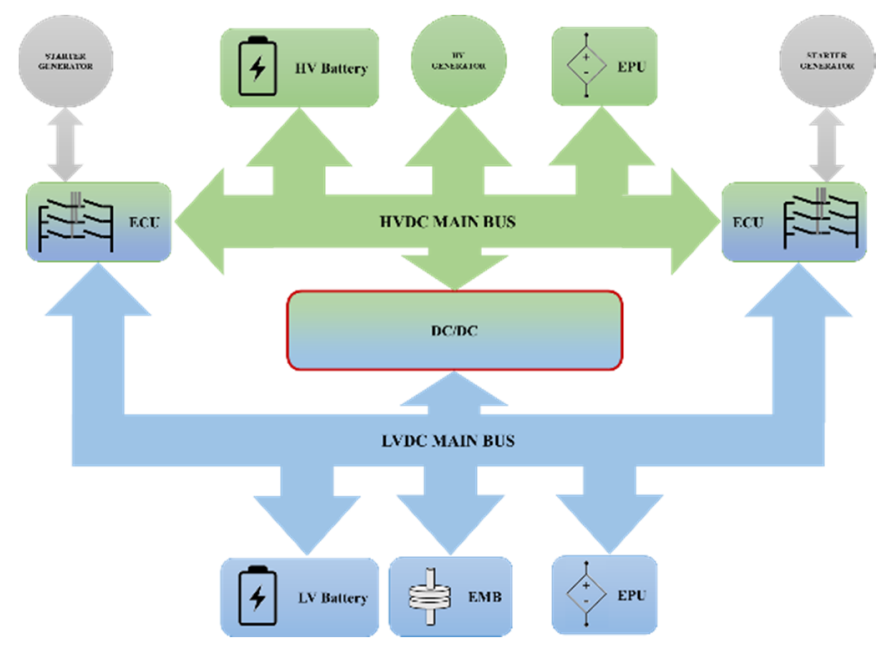

Fig. 1. Aircraft distribution network under investigation.

As shown in Fig.1, an isolated, bidirectional DC/DC converter has to be included in the system in order to provide an active interface between the two DC networks [29], [30]. The converter must be designed to provide high power density and high efficiency, to be integrated in the aircraft structure with minimum impact on volume, weight and heat management. At the same time, it must provide reliable and flexible operation, also capable to respond to fault events or other abnormal operating conditions with a controlled and predictable behaviour, while minimising the impact on power generation. In particular, the reliability of the DC-DC converter is crucial during "emergency flight" operation, as it will supply the essential equipment to guarantee flight safety. The converter will also operate in a stringent and harsh environment, including limited cooling capabilities; pressure drops, mechanical vibrations and possible EMC or lightning interference, and their operation should have minimum effect on the environment. In order to achieve these challenging requirements, it is clear that cutting-edge technological innovations and innovative design approaches will be required.

Several isolated DC/DC converter topologies are proposed in literature. Flyback and Forward, and Forward-Flyback converters are investigated in [31], [32] and [33] respectively. These topologies requires a minimal number of active devices, however, their low efficiency, compared with other converter structures limits their use in high power applications. Resonant 
converters, such as isolated LLC resonant DC/DC converter [34], [35] and Series Resonant (SR) converter [36] can also be considered for this application. They take advantage of resonant networks in order to achieve Zero Voltage Switching (ZVS) or Zero Current Switching (ZCS) commutations, providing highly efficient power conversion. However, additional passive components are needed and control becomes challenging when a wide operating area is required by the application. On the other hand, Dual-Active-Bridge (DAB) [37] and Three-Phase DualActive-Bridge [38] present lower loss switching loss due to their natural capability of achieving ZVS commutation when the devices are turned on, in a wide operating range and without drastically increase the control system complexity. Similarly to the DAB, an Interleaved Boost with Coupled Inductors (IBCI) converter has been proposed in [39], that provides ZVS operation while presenting active control of the output current, thus requiring reduced capacitive filter, which makes it particularly suitable for high power low voltage applications.

Based on these considerations only DAB and IBCI are investigated in this paper, together with another topology, specifically designed for this application and named Active Bridge Active Clamp (ABAC) converter. In the following sections, these three topologies are analysed in terms of design, operating capabilities and weight and volume considerations.

\section{TOPOLOGIES UNDER EVALUATION}

The three topologies under investigation are shown Fig. 2. The DAB converter [40], [41], shown in Fig. 2 (a) is a wellknown topology, which provides efficient DC/DC conversion as well as galvanic insulation. On the other hand the IBCI converter [39] replace the H-Bridge on the LV side of DAB with two clamping circuits, and the high frequency transformer with two coupled inductors, as shown in Fig. 2 (b). Compared to the DAB, the IBCI converter can actively control the load current allowing an accurate converter current overload limitation.

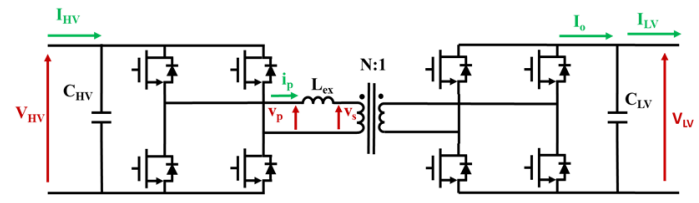

(a) The Dual Active Bridge (DAB)

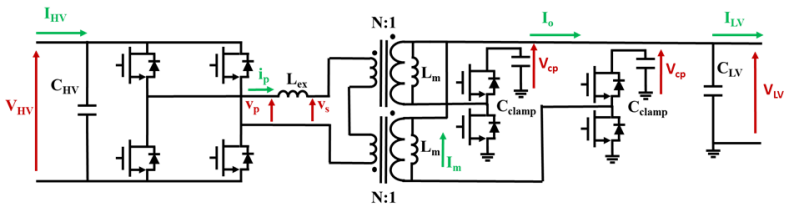

(b) The Interleaved Boost with Coupled Inductors (IBCI)

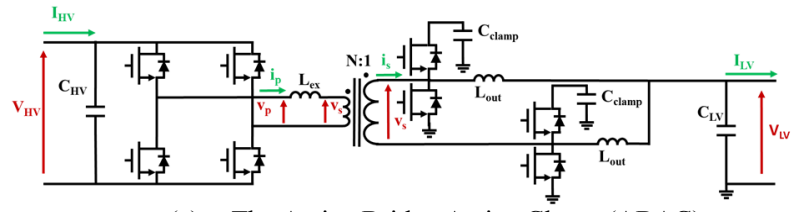

(c) The Active Bridge Active Clamp (ABAC)

Fig. 2. Topologies under investigation.

Finally, the ABAC converter represents an alternative to the IBCI where, instead of two coupled inductors, a high frequency transformer and two output inductors are used, as shown in Fig. 2 (c). The working principle is similar to the IBCI; however the arrangements of passive components may results in an increased power density, thus reducing the overall converter weight and volume. The basic design procedures for the three topologies are discussed in detail in the following subsections.

\section{A. Control and Modulation}

All three topologies can share the same control scheme and modulation approach as shown in Fig. 3 and Fig. 4.

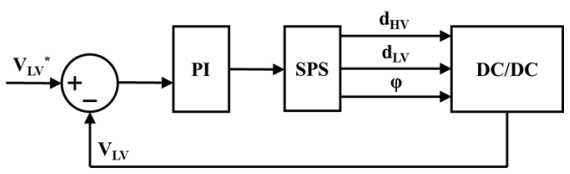

Fig. 3. Control block diagram.

Conventional Single Phase Shift (SPS) modulation scheme [42] is adopted. With SPS the duty cycle of each bridge/arm is kept constant at $50 \%$ of the sampling period, while the phase shift $\varphi$ between the transformer primary and secondary voltage waveform is used to control the power transfer. A Proportional Integral (PI) controller is designed in order to regulate the output voltage as illustrated in Fig. 3.

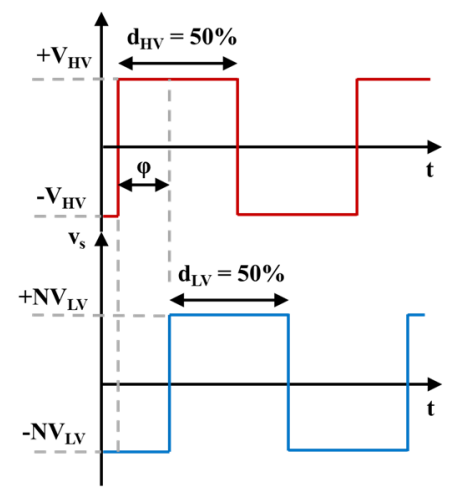

Fig. 4. SPS modulation operating principle.

\section{B. Design of the Dual Active Bridge}

As shown in Figure 2 (a), the DAB consists of two H-Bridge linked on their $\mathrm{AC}$ sides with a series inductor and an $\mathrm{HF}$ transformer. Theoretical operation waveforms for such topology is drawn in Fig. 5, where $\mathrm{V}_{\mathrm{p}}$ and $\mathrm{V}_{\mathrm{s}}$ are transformer primary and secondary voltages, which operate at $50 \%$ duty cycle in SPS modulation, $\mathrm{i}_{\mathrm{p}}$ is transformer primary current. $\mathrm{I}_{\mathrm{o}}$ and $\mathrm{I}_{\mathrm{LV}}$ are the currents flowing before and after being filtered by the output capacitor $\mathrm{C}_{\mathrm{LV}}$. It is noted that the output current $\mathrm{I}_{0}$ has considerably large ripple which needs a significantly large capacitive filter to suppress the ripple on $\mathrm{V}_{\mathrm{LV}}$. The power transfer inductance $\mathrm{L}_{\mathrm{ex}}$ on the primary side is designed in order to achieve the required power rating for the converter [37],

$$
L_{e x}=\frac{N V_{H V} V_{L V}}{8 f_{s} P_{\max }}
$$

where, $\mathrm{N}$ is transformer turn ratio, $\mathrm{V}_{\mathrm{HV}}$ and $\mathrm{V}_{\mathrm{LV}}$ are high $\mathrm{DC}$ bus voltage and low DC bus voltage respectively, $\mathrm{f}_{\mathrm{s}}$ is switching frequency and $\mathrm{P}_{\max }$ is the rated power. 


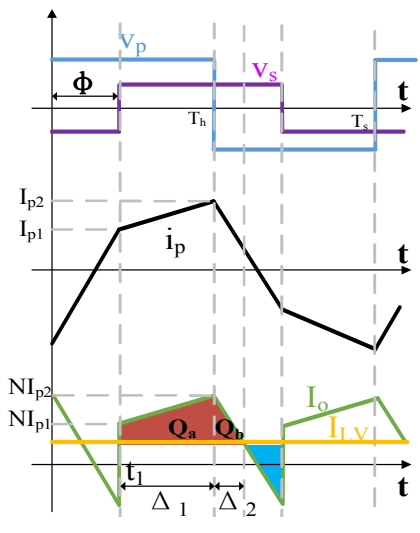

Fig. 5. Main aveforms for a conventional DAB with SPS modulation

In order to design the filter capacitors, $\mathrm{I}_{\mathrm{p} 1}$ and $\mathrm{I}_{\mathrm{p} 2}$ in Fig. 5 can be calculated through following equations [37], where, $T_{h}$ is half of the switching period.

$$
\begin{aligned}
I_{p 1} & =\frac{T_{h}}{2 L_{e x}}\left(2 V_{H V} \frac{\varphi}{\pi}-V_{H V}+N V_{L V}\right) \\
I_{p 2} & =\frac{T_{h}}{2 L_{e x}}\left(2 N V_{L V} \frac{\varphi}{\pi}+V_{H V}-N V_{L V}\right)
\end{aligned}
$$

Referring to Fig. 5, the time iintervals $\Delta_{1}$ and $\Delta_{2}$ can be calculated using the following equations:

$$
\begin{gathered}
I_{p 1}+\frac{V_{H V}-N V_{L V}}{L_{e x}} \Delta_{1}=I_{p 2} \\
I_{p 2}-\frac{I_{L V}}{N}=\frac{V_{H V}+N V_{L V}}{L_{e x}} \Delta_{2}
\end{gathered}
$$

Rearranging equation (4) and (5) yields to:

$$
\begin{gathered}
\Delta_{1}=\frac{I_{p 2}-I_{p 1}}{V_{H V}-N V_{L V}} L_{e x} \\
\Delta_{2}=\frac{I_{p 2}-\frac{I_{L V}}{N}}{V_{H V}+N V_{L V}} L_{e x}
\end{gathered}
$$

Therefore, the peak to peak output voltage ripple $r_{V}$ can be obtained based on following equation:

$$
r_{V}=\frac{\Delta V_{L V}}{V_{L V}}=\frac{\int_{t_{1}}^{t_{1}+\Delta_{1}+\Delta_{2}}\left(I_{o}-I_{L V}\right) d t}{V_{L V}}=\frac{Q_{a}+Q_{b}}{C_{L V} V_{L V}}
$$

where,

$$
\begin{gathered}
Q_{a}=\frac{\left(N I_{p 1}-I_{L V}\right)+\left(N I_{p 2}-I_{L V}\right)}{2} \Delta_{1} \\
Q_{b}=\frac{\left(N I_{p 2}-I_{L V}\right)}{2} \Delta_{2}
\end{gathered}
$$

The output capacitor $\mathrm{C}_{\mathrm{LV}}$ can then be derived from (7) as:

$$
C_{L V}=\frac{Q_{a}+Q_{b}}{r_{V} V_{L V}}
$$

A similar approach can be used to calculate the value of $\mathrm{C}_{\mathrm{HV}}$. In order to analyse the ZVS operating area for the DAB converter the voltage transfer ratio $\mathrm{M}$ is defined:

$$
M=\frac{N V_{L V}}{V_{H V}}
$$

Considering that ZVS is achieved when $\mathrm{I}_{\mathrm{p} 1}>0$ and $\mathrm{I}_{\mathrm{p} 2}>0$, from (2), (3) and (12) the following conditions can be obtained

$$
\begin{aligned}
& \frac{(1-M) \pi}{2}<\varphi, \text { if } \mathrm{M}<1 \\
& \frac{(M-1) \pi}{2 M}<\varphi, \text { if } \mathrm{M}>1
\end{aligned}
$$

In Fig. 6, the boundaries (13) and (14) are plotted, showing that when $M=1, Z V S$ turn on can be achieved in the entire power range for both primary and secondary switches.

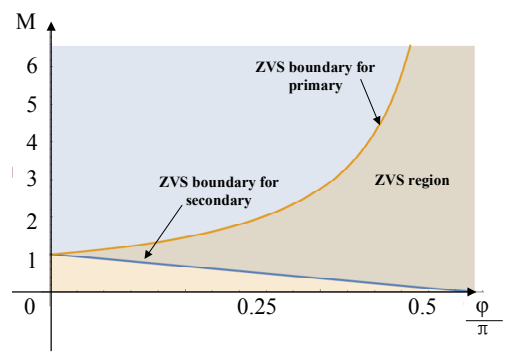

Fig. 6. Soft switching region for DAB. Region for primary bridges (aera coloured in yellow) and secondary bridges ( area coloured in blue). Overlapping is ZVS for all switches

\section{Design of the Interleaved Boost with Coupled inductors}

The IBCI converter features a similar operating behaviour to the $\mathrm{DAB}$, with the main difference is that it provides a current fed LV stage, taking advantage of the coupled inductors. As for the $\mathrm{DAB}$, the power transfer inductor $\mathrm{L}_{\mathrm{ex}}$ transfers power from primary to the clamping stages, while the magnetizing inductors $\mathrm{L}_{\mathrm{m}}$ serves as buffers to transfer energy from the clamping bridges to the LV output. When using SPS modulation, the switches are all operating at $50 \%$ duty, and two clamping bridges are complementarily switched in order to produce a square waveform across the two primary windings connected in anti-series. The IBCI features an interleaved LV output current. The design of the input capacitor $\mathrm{C}_{\mathrm{HV}}$ is identical to the one in DAB. Similarly, the power transfer inductor $L_{e x}$ can be designed in order to obtain the required power transfer:

$$
L_{e x}=\frac{N V_{H V} V_{c}}{8 f_{s} P_{\max }}
$$

where $\mathrm{V}_{\mathrm{c}}$ is the voltage on the clamping capacitors and has an average amplitude of twice the amplitude of $\mathrm{V}_{\mathrm{LV}}$. Ideally, the output current $\mathrm{I}_{\mathrm{LV}}$ is $\mathrm{DC}$ with zero ripple, due to the interleaved output property of this converter and, thus, there is no need for capacitive filter on the LV side of the converter. However, a filter capacitance is used to filter out the current ripple related to converter asymmetries and load harmonics and to improve the dynamic response to load changes if needed. The magnetising inductors $\mathrm{L}_{\mathrm{m}}$ act as output inductance. Assuming a desired 
current ripple before the interleaved point of $\mathrm{r}_{\mathrm{I}}$, the current ripple constraint for $\mathrm{L}_{\mathrm{m}}$ can be defined as:

$$
\frac{2 V_{L V}{ }^{2} T_{h}}{r_{I} P_{\max }}<L_{m}
$$

Regarding ZVS turn on operating region for the IBCI, the primary side boundary condition is exactly the same as the one calculated for the DAB in (13). On the other hand, ZVS condition for secondary clamping circuits is defined as follows

$$
\mathrm{I}_{\mathrm{m}}(\varphi)<I_{p 1} N
$$

where $I_{m}(\phi)$ and $I_{p 1}$ are obtained from Fig. 7 as

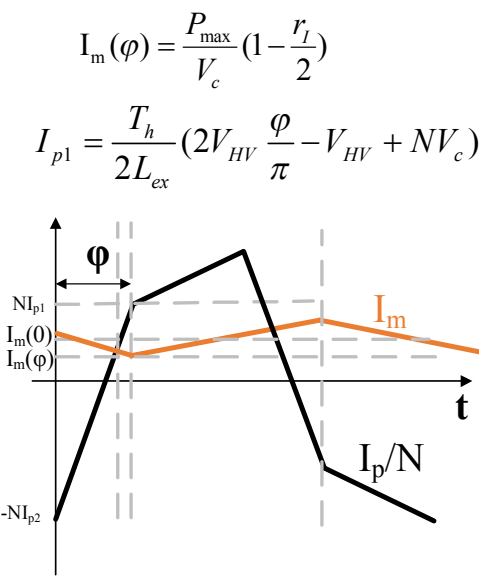

Fig. 7. Illustration of maganitizing current $I_{m}$ and transformer current $I_{p}$

Thus M' is defined as follows

$$
M^{\prime}=\frac{N V_{c}}{V_{H V}}
$$

Substituting (15), (18), (19) and (20) into (17) yields to:

$$
M^{\prime}>\frac{6-r_{I}-8 \frac{\varphi}{\pi}}{4}
$$

According to (21), $\mathrm{r}_{\mathrm{I}}$ has rather small weight in determining M'. The ZVS region for IBCI can be drawn as in Fig. 8, which shows a smaller area than the one shown for the DAB in Fig. 6, i.e. soft turn on is lost at low power transfer.

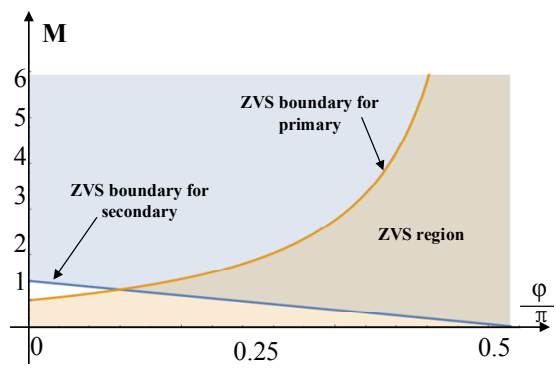

Fig. 8. Soft switching region for IBCI and ABAC. Primary bridges (aera coloured in yellow) and secondary bridges ( area coloured in blue). Overlapping is ZVS for all switches

\section{Design of the Active Bridge Active Clamp (ABAC) converter}

The ABAC converter beaves similarly to the IBCI. An inductor $\mathrm{L}_{\mathrm{ex}}$ transfers power from the primary to the clamping stages while the two coupled inductors are replaced with a high frequency transformer and two discrete output inductors. The transformer magnetising inductance has much lower current than the ones in the IBCI, thus it can be neglected in this analysis. Two output inductors $\mathrm{L}_{\text {out }}$ serve as buffers to transfer energy from the clamping bridges to the LV output. When using SPS modulation, the switches are all operating at 50\% duty, and the two clamping bridges are complementarily switched in order to impose a squarewave voltage across the transformer secondary.

The design of the power transfer inductor $L_{e x}$ and input capacitor $\mathrm{C}_{\mathrm{HV}}$ are identical to the one in DAB. As for the IBCI, the output current $\mathrm{I}_{\mathrm{LV}}$ is ideally $\mathrm{DC}$ with zero ripple, due to the interleaved output property of this converter and, thus, a filter capacitance is used only to filter out the current ripple related to converter asymmetries and load harmonics and for dynamic load changes. Regarding parameters design and soft switching analysis, the ABAC calls for the exactly same procedures already discussed for the IBCI where, instead of the coupled inductors magnetising inductance, two external inductors are considered. The main advantage of the ABAC converter with respect to the IBCI resides in the more compact design of the high frequency transformer, with respect to the coupled inductors design which has to take into account the required DC flux for the converter to operate. This will impact the design in terms of converter weight, as the magnetic core flux capability is not fully exploited in the IBCI.

\section{SIMULATION RESULTS}

Simulations are carried out considering the parameters of Table I in buck operation, i.e. when power is transferred from an HV source to a LV load. Fig. 9 shows steady state operations when the three converters are providing $10 \mathrm{~kW}$ on the low voltage DC bus. Results show similar input/output performance of the three topologies under investigation. As it can be noted, the DAB presents a considerable current ripple on the LV output, which has to be filtered through the LV capacitor, while IBCI and ABAC present a continuous LV output current with minimum ripple.

TABLE I. DESIGN PARAMETERS FOR THE TOPOLOGIES UNDER EVALUATION

\begin{tabular}{|c||c|c|c|c|}
\hline Description & Symbol & DAB & IBCI & ABAC \\
\hline \hline Switching Frequency & $\mathrm{f}_{\mathrm{sw}}$ & $100 \mathrm{kHz}$ & $100 \mathrm{kHz}$ & $100 \mathrm{kHz}$ \\
\hline Sampling Time & $\mathrm{T}_{\mathrm{s}}$ & $10 \mu \mathrm{s}$ & $10 \mu \mathrm{s}$ & $10 \mu \mathrm{s}$ \\
\hline Rated Output Power & $\mathrm{P}_{\mathrm{out}}$ & $10 \mathrm{~kW}$ & $10 \mathrm{~kW}$ & $10 \mathrm{~kW}$ \\
\hline Input Voltage & $\mathrm{V}_{\mathrm{HV}}$ & $270 \mathrm{~V}$ & $270 \mathrm{~V}$ & $270 \mathrm{~V}$ \\
\hline Output Voltage & $\mathrm{V}_{\mathrm{LV}}$ & $28 \mathrm{~V}$ & $28 \mathrm{~V}$ & $28 \mathrm{~V}$ \\
\hline Power Transfer inductance & $\mathrm{L}_{\mathrm{ex}}$ & $7.56 \mu \mathrm{H}$ & $7.56 \mu \mathrm{H}$ & $7.56 \mu \mathrm{H}$ \\
\hline Input Filter Capacitance & $\mathrm{C}_{\mathrm{HV}}$ & $20 \mu \mathrm{F}$ & $20 \mu \mathrm{F}$ & $20 \mu \mathrm{F}$ \\
\hline Output Filter Capacitance & $\mathrm{C}_{\mathrm{Lv}}$ & $3 \mathrm{mF}$ & $50 \mu \mathrm{F}$ & $20 \mu \mathrm{F}$ \\
\hline Clamp Capacitance & $\mathrm{C}_{\mathrm{clamp}}$ & $/$ & $100 \mu \mathrm{F}$ & $2.5 \mu \mathrm{F}$ \\
\hline Output Inductance & $\mathrm{L}_{\mathrm{out}}$ & $/$ & $/$ & $3 \mu \mathrm{H}$ \\
\hline Coupled Inductors & $\mathrm{L}_{\mathrm{mag}}$ & $/$ & $50 \mu \mathrm{H}$ & $/$ \\
\hline Magnetizing Inductance & & & & \\
\hline
\end{tabular}


Fig. 10 shows the behaviour of the three converters when a short circuit is applied on the LVDC bus, with a short circuit resistance of $10 \mathrm{~m} \Omega$, at time $1.5 \mathrm{~s}$. In this case the DAB converter presents high current ripple on the LV output that could be harmful for the converter depending on the duration of the fault, while IBCI and ABAC present a continuous LV output current

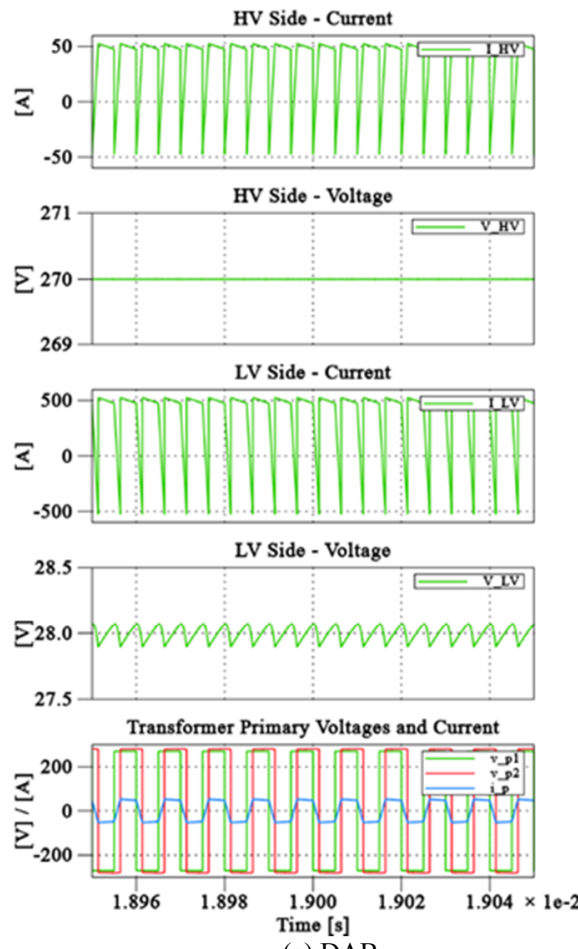

(a) DAB
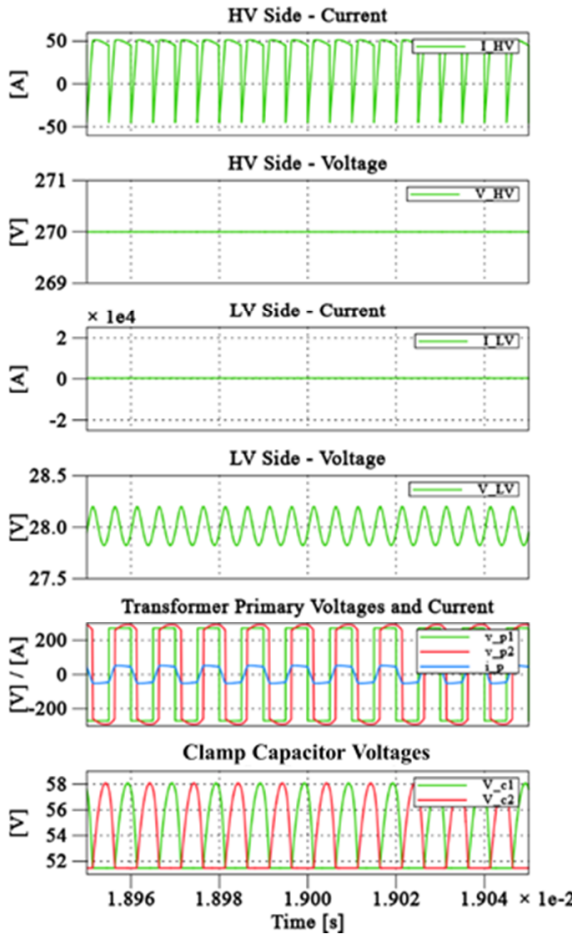

(b) IBCI
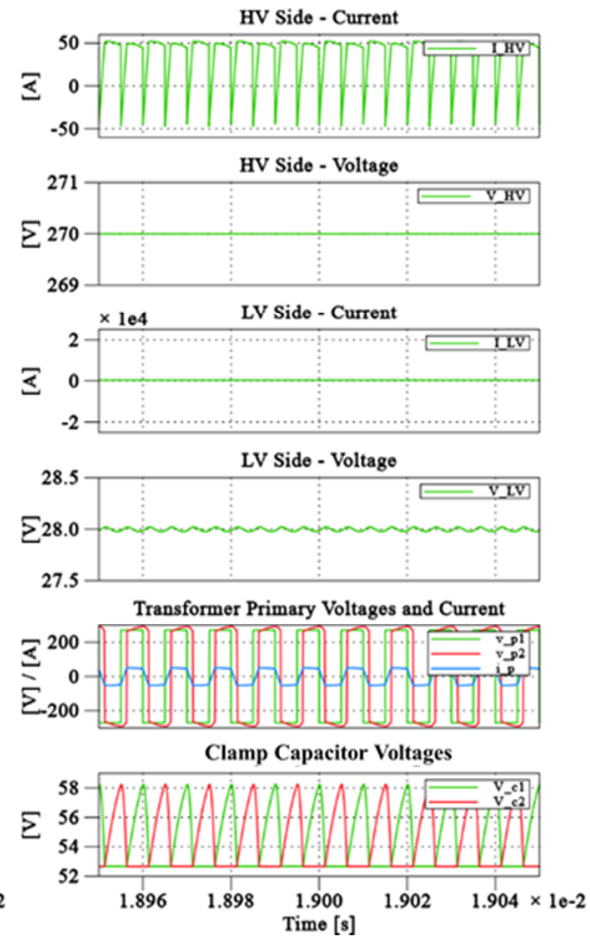

(c) ABAC

Fig. 9. Buck mode steady state results when the converters are providing $10 \mathrm{~kW}$ on the low voltage $\mathrm{DC}$ bus.
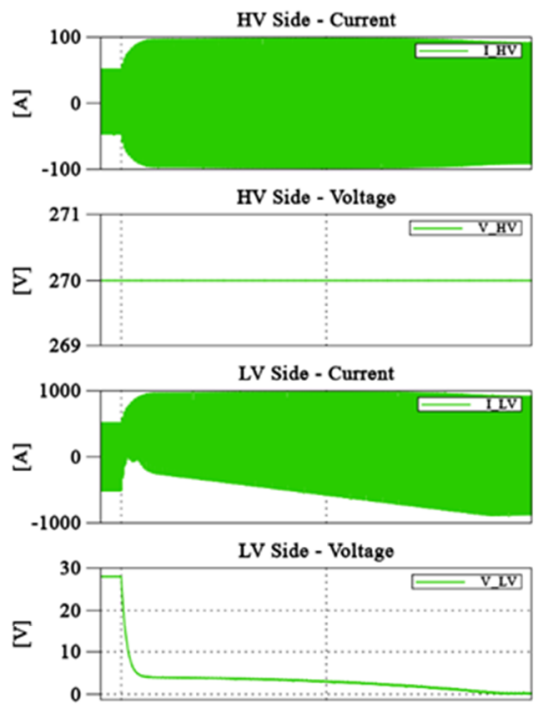

Transformer Primary Voltages and Current

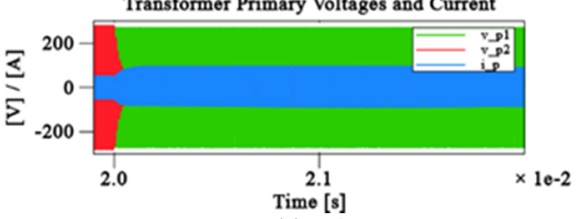

(a) DAB

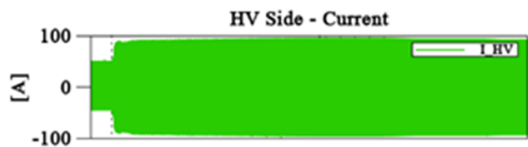

HV Side - Voltage
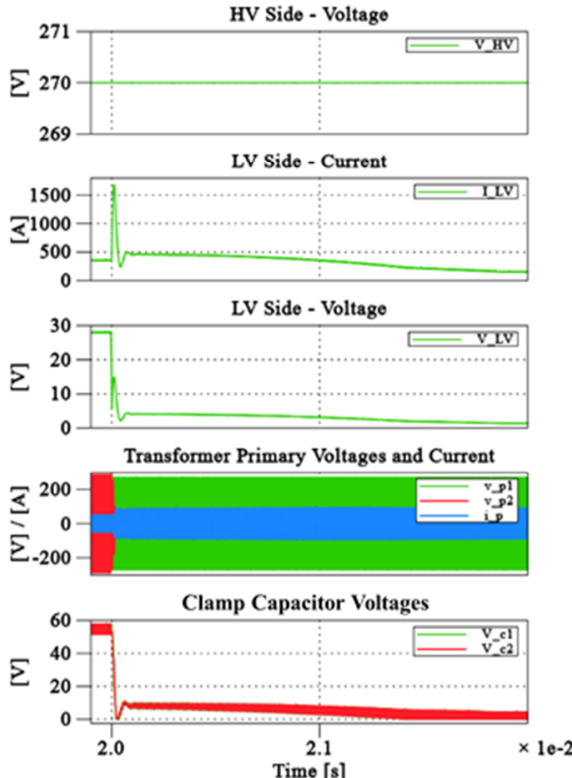

(b) IBCI
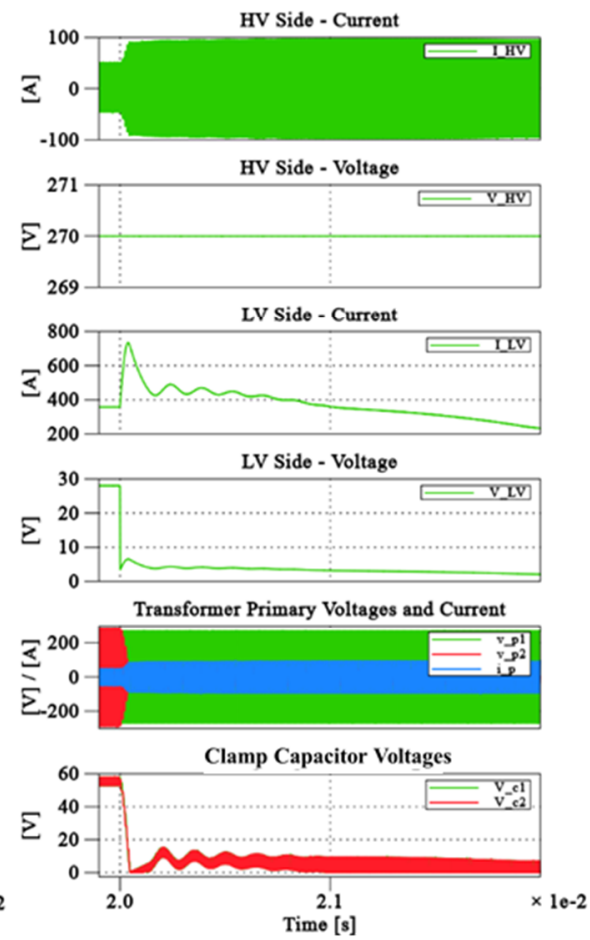

(c) ABAC

Fig. 10. Buck mode results during a short circuit on low voltage DC bus with a short circuit resistance of $10 \mathrm{~m} \Omega$. 
In order to perform an efficiency comparison between these three topologies, the power electronics devices has been selected accordingly with the required voltage and current rating and paralleled in order to increase the converter current rating or efficiency. In particular, the IPT02N10N3 Silicon Mosfet, manufactured by Infineon and rated 100V, 300A has been selected for the converter LV side, while the C2M0025120D Silicon Carbide Mosfet, manufactured by Wolfspeed and rated $1.2 \mathrm{kV}, 90 \mathrm{~A}$ has been selected for the high voltage side. Regarding the passive components, such as capacitors, transformers and inductors, their behaviour has been considered ideal during the comparison, thus limiting the loss analysis to semiconductors. The efficiency is calculated through PLECS simulation. The results, shown in Fig, 11, highlight the low device losses for these three topologies when the soft switching constraints are satisfied.

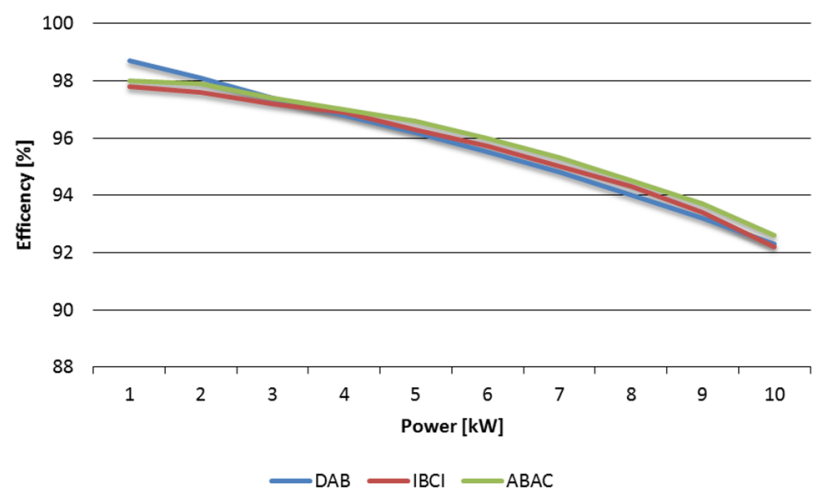

Fig. 11. Converter efficiency for the topologies under different operating conditions.

\section{WEIGHT AND VOLUME CONSIDERATIONS}

A first basic estimation of weight and volume for the three topologies has been calculated by considering off the shelf components and their datasheet information, shown in Table II, combined with the design parameters. The weight and volume estimation includes also a first evaluation of the heatsink weight and volume but does not comprises the additional weight and volume of PCB boards, wiring and other components. The results in Fig. 12, show that the DAB presents a low weight but a relatively high volume, mainly related with the size of the low voltage side filtering capacitors. On the other hand the IBCI presents a lower volume compared to the DAB, but an higher weight, related with the necessity to include two coupled inductors whit a considerable DC flux.

TABLE II. OFF THE SHELF COMPONENTS USED FOR THE WEIGHT AND VOLUME EVALUATION

\begin{tabular}{|c||l|c|c|}
\hline Components & \multicolumn{1}{|c|}{ Description } & $\begin{array}{c}\text { Weight } \\
{[\mathbf{k g}]}\end{array}$ & $\begin{array}{c}\text { Volume } \\
{[\mathbf{I ]}}\end{array}$ \\
\hline \hline $\begin{array}{c}\text { LV } \\
\text { Capacitor }\end{array}$ & $\begin{array}{l}\text { SMD Multilayer Ceramic } \\
\text { Capacitor, C Series, } 1 \mu \mathrm{F}, \pm \\
10 \%, \text { X7R, } 100 \mathrm{~V}\end{array}$ & 0.0001 & 0.0036 \\
\hline $\begin{array}{c}\text { HV } \\
\text { Capacitor }\end{array}$ & $\begin{array}{l}\text { Film Capacitor, B32774 Series, } \\
10 \mu F, \pm 10 \%, 450 \mathrm{~V}\end{array}$ & 0.05 & 0.0116 \\
\hline Transformer & $\begin{array}{l}\text { STANDEX Series P560 8.4kW } \\
\text { 50kHZ 10:1+1 }\end{array}$ & 0.7 & 0.1843 \\
\hline HV Device & $\begin{array}{l}\text { CREE C2M0025120D Power } \\
\text { MOSFET, 90A, 1.2 kV }\end{array}$ & 0.0011 & 0.0035 \\
\hline LV Device & $\begin{array}{l}\text { INFINEON IPTO20N10N3 } \\
\text { MOSFET, 300A, 100 V }\end{array}$ & 0.0014 & 0.0003 \\
\hline Heatsink & MERSER 61070 & 0.4758 & 0.6374 \\
\hline Fan & $\begin{array}{l}\text { SANYO DENKI - SANACE } \\
\text { 9CRE0412P5J03 Axial Fan }\end{array}$ & 0.126 & 0.0896 \\
\hline
\end{tabular}

Finally, for the specific ratings considered in the application, the ABAC appears to be the most performing in terms of weight and volume. In fact, since the LV side is current fed, it does not require an high value of filtering capacitance while when looking at the magnetics, the $\mathrm{ABAC}$ converter requires an high frequency transformer, exactly as for the DAB converter, plus two output inductor with a small inductance value which do not impact the design noticeably.

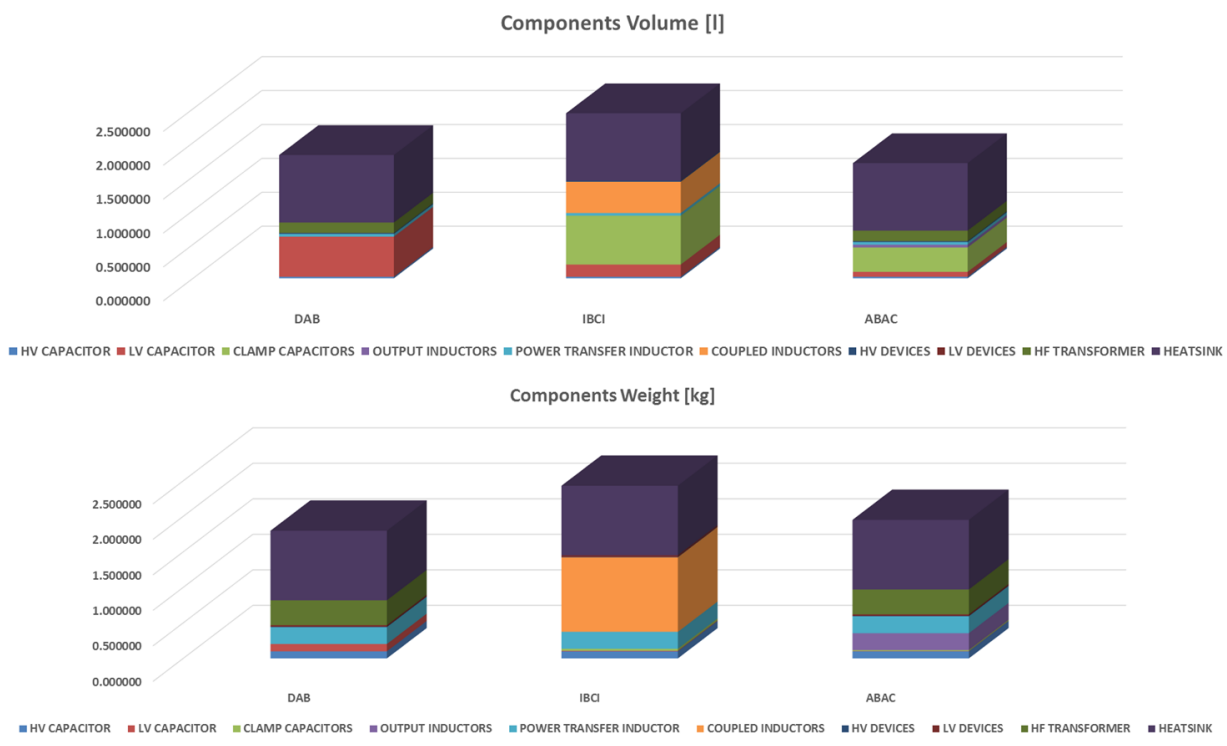

Fig. 12. Weight and volume estimation for the topologies under investigation. 


\section{EXPERIMENTAL RESULTS}

A $10 \mathrm{~kW}$ experimental prototype based on the ABAC converter has been manufactured, as shown in Fig. 13. Differently from the ABAC converter discussed so far, the low voltage side has been split in two submodules in order to reduce the current conducted by the low voltage devices without excessively increase the components number. Moreover, the power transfer inductor $\mathrm{L}_{\mathrm{ex}}$ has been divided on each of the HF transformer secondary, in order to decouple the two secondary windings.

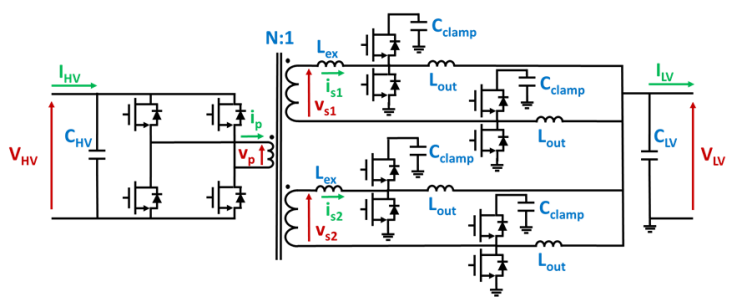

(a)

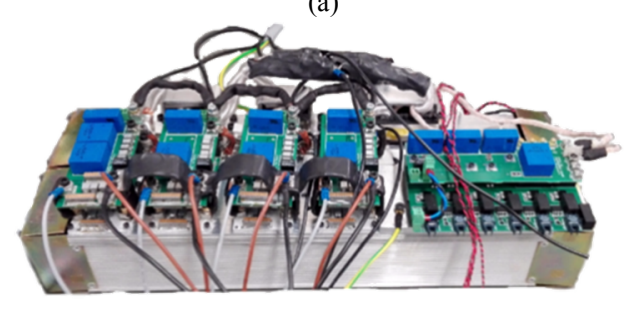

(b)

Fig. 13. ABAC Converter prototype: (a) schematic (b) practical realization.

Experimental results are shown in Fig. 14 when the converter is operating in buck on a resistive load. The results are obtained considering a switching frequency of $100 \mathrm{kHz}$ and a power transferred to the load of $5600 \mathrm{~W}$, which results in a DC load current of 200A. Voltages and currents at primary and one secondary of the HF transformer are presented, as well as voltage and current on both converter external interfaces (supply and load). The load voltage is well regulated at $28 \mathrm{~V}$, while providing the $200 \mathrm{~A}$ load current without any noticeable oscillation. On the other hand, looking at the current flowing through one of the four output inductors, it is possible to notice that the triangular ripple, which is cancelled at the load point, matches the value previously obtained in simulations.

\section{CONCLUSIONS}

In this work an evaluation of isolated DC/DC converter topologies for aerospace applications has been carried out. Three topologies have been selected, respectively DAB, IBCI and $\mathrm{ABAC}$ converters, and compared in terms efficiency, weight and volume for the specific application of a $270 \mathrm{~V} / 28 \mathrm{~V} 10 \mathrm{~kW}$ bidirectional DC/DC converter. From this analysis the ABAC represents a promising alternative to the $\mathrm{DAB}$, able to reduce the converter volume when high power ratings are considered. Based on these considerations, an experimental prototype has been manufactured and tested validating the performances expected from simulations.

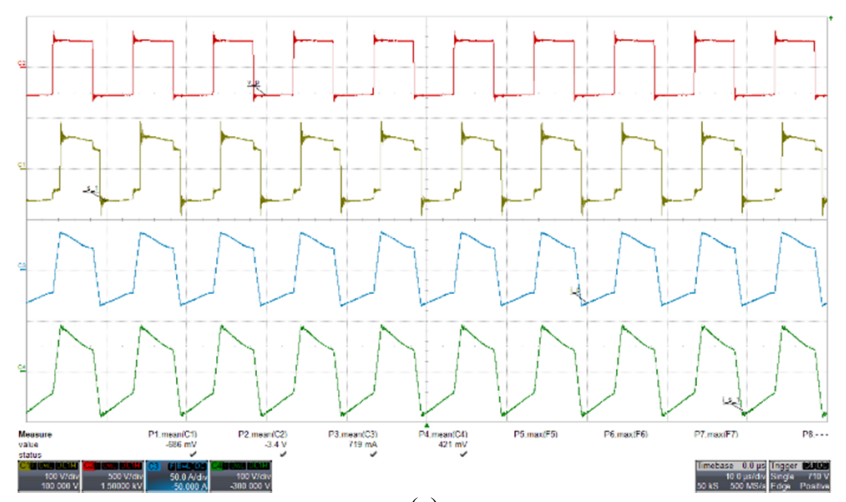

(a)

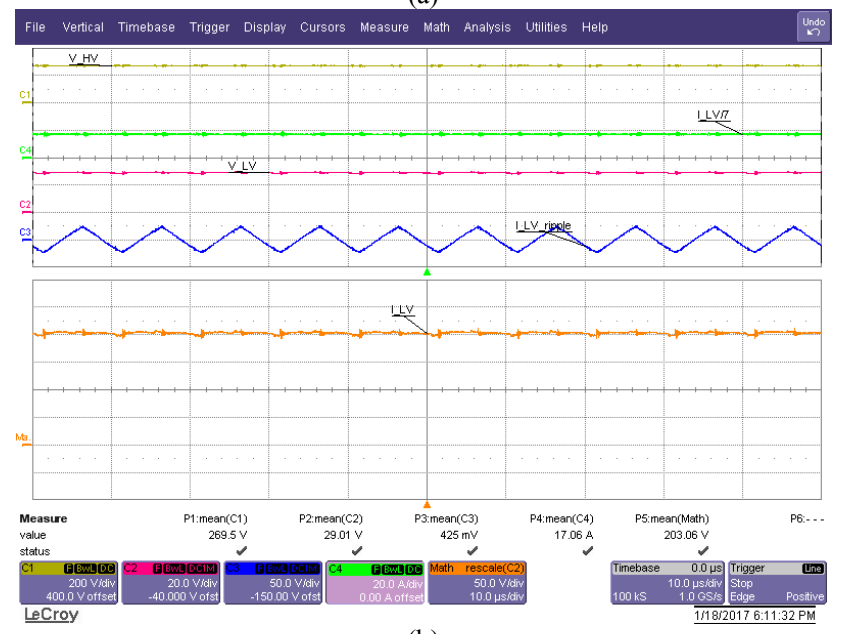

(b)

Fig. 14. Experimental results for the proposed ABAC topology.(a) HF transformer primary voltage (red, $500 \mathrm{~V} /$ div), $\mathrm{HF}$ transformer secondary voltage (yellow, 100V/div), HF transformer primary current (blue, 50A/div), HF transformer secondary current (green, 100A/div); (b) HV supply voltage (yellow, 200V/div), load current divided by 7 (green, 20A/div) load voltage (magenta, 20V/div), current ripple on one output inductor (blue, $50 \mathrm{~A} / \mathrm{div}$ ) total load current (orange, $50 \mathrm{~A} / \mathrm{div}$ ).

\section{ACKNOWLEDGMENT}

The research leading to these results has received funding from the European Union's Seventh Framework Programme (FP7/2009-2018) Clean Sky Joint Technology Initiative. See www.cleansky.eu

\section{REFERENCES}

[1] P. Wheeler and S. Bozhko, "The More Electric Aircraft," IEEE Electrif. Mag., vol. 2, no. 4, pp. 6-12, 2014.

[2] A. Trentin, P. Zanchetta, P. Wheeler, and J. Clare, "Power conversion for a novel AC / DC aircraft electrical distribution system," IET Electr. Syst. Transp., no. February 2013, pp. 29-37, 2014.

[3] J. A. Rosero, J. A. Ortega, E. Aldabas, and L. Romeral, "Moving Towards a More Electric Aircraft," IEEE Aerosp. Electron. Syst. Mag., vol. 22, no. 3, pp. 3-9, 2007.

[4] B. Sarlioglu and C. T. Morris, "More Electric Aircraft: Review , Challenges , and Opportunities for Commercial Transport Aircraft," IEEE Trans. Transp. Electrif., vol. 1, no. 1, pp. 54-64, 2015.

[5] C. I. Hill, S. Bozhko, T. Yang, P. Giangrande, and C. Gerada, "More Electric Aircraft Electro-Mechanical Actuator Regenerated Power Management," IEEE Int. Symp. Ind. Electron., pp. 2163-5145, 2015.

[6] S. S. Yeoh, T. Yang, L. Tarisciotti, C. I. Hill, S. Bozhko, and P. Zanchetta, "More Electric Aircraft Starter-Generator System with Utilization of 
Hybrid Modulated Model Predictive Control," Electr. Syst. Aircraft, Railw. Sh. Propuls. Road Veh. Int. Transp. Electrif. Conf., 2016.

[7] S. S. Yeoh, T. Yang, L. Tarisciotti, S. Bozhko, and P. Zanchetta, "Hybrid modulated model predictive control for the more electric aircraft generator system," Electr. Syst. Aircraft, Railw. Sh. Propulsion, ESARS, 2015.

[8] R. T. Naayagi, "A Review of More Electric Aircraft Technology," Int. Conf. Energy Effic. Technol. Sustain., pp. 750-753, 2013.

[9] K. Areerak, S. V. Bozhko, G. M. Asher, L. De Lillo, and D. W. P. Thomas, "Stability Study for a Hybrid AC-DC More-Electric Aircraft Power System," IEEE Trans. Aerosp. Electron. Syst., vol. 48, no. 1, pp. 329-347, 2012.

[10] I. Christou, A. Nelms, I. Cotton, and M. Husband, "Choice of optimal voltage for more electric aircraft wiring systems," IET Electr. Syst. Transp., vol. 1, no. 1, pp. 24-30, 2011.

[11] M. Tariq, A. I. Maswood, C. J. Gajanayake, and A. K. Gupta, "Aircraft batteries: current trend towards more electric aircraft," IET Electr. Syst. Transp., vol. 7, no. 2, pp. 93-103, 2017.

[12] M. Tariq, Ali I. Maswood, C. J. Gajanayake, G. H. P. Ooi, P. Chatterjee, S. Madishetti, D. A. Molligoda, and A. K. Gupta, "Battery integration with more electric aircraft DC distribution network using phase shifted high power bidirectional DC-DC converter," IEEE PES Asia-Pacific Power Energy Eng. Conf., 2015.

[13] V. Venkataramanan, A. Mallikeswaran, and A. Srivastava, "Analysis of Aircraft Electric Microgrid System with Auxiliary Power Unit Using Real Time Simulation," IEEE Int. Symp. Ind. Electron., pp. 245-250, 2015.

[14] S. De, M. Rajne, S. Poosapati, C. Patel, and K. Gopakumar, "Lowinductance axial flux BLDC motor drive for more electric aircraft," IET Power Electron., vol. 5, no. 1, pp. 124-133, 2012.

[15] O. Bottauscio, G. Serra, M. Zucca, and M. Chiampi, "Role of Magnetic Materials in a Novel Electrical Motogenerator for the More Electric Aircraft," IEEE Trans. Magn., vol. 50, no. 4, pp. 1-4, 2014.

[16] W. U. N. Fernando, M. Barnes, and O. Marjanovic, "Direct drive permanent magnet generator fed $\mathrm{AC}-\mathrm{DC}$ active rectification and control for more-electric aircraft engines," IET Electr. Power Appl., vol. 5, no. 1, pp. 14-27, 2011.

[17] M. Hirst, A. Mcloughlin, P. J. Norman, and S. J. Galloway, "Demonstrating the more electric engine: a step towards the power optimised aircraft," IET Electr. Power Appl., vol. 5, no. 1, pp. 3-13, 2011.

[18] E. Ganev, "Selecting the best electric machines for electrical powergeneration systems: High-performance solutions for aerospace More electric architectures," IEEE Electrif. Mag., vol. 2, no. 4, pp. 13-22, 2014.

[19] R. A. Mastromauro, S. Stasi, F. Gervasio, and M. Liserre, "A Ground Power Unit Based on Paralleled Interleaved Inverters for a More-ElectricAircraft," Int. Symp. Power Electron. Electr. Drives, Autom. Motion, pp. 216-221, 2014.

[20] W. Rohouma, P. Zanchetta, P. W. Wheeler, and L. Empringham, “A FourLeg Matrix Converter Ground Power Unit With Repetitive Voltage Control," IEEE Trans. Ind. Electron., vol. 62, no. 4, pp. 2032-2040, 2015.

[21] A. Trentin, P. Zanchetta, P. Wheeler, and J. Clare, "Power flow analysis in electro-mechanical actuators for civil aircraft," IET Electr. Power Appl., vol. 5, no. 1, p. 48, 2011.

[22] M. Villani, M. Tursini, G. Fabri, and L. Castellini, "Electromechanical Actuator for Helicopter Rotor Damper Application," IEEE Trans. Ind. Appl., vol. 50, no. 2, pp. 1007-1014, 2014.

[23] A. Nothofer, L. Tarisciotti, Q. Zhou, T. Benson, S. Greedy, and C. Christopoulos, "Analysis of conducted emissions from an Electric Nacelle Anti-Ice Power Control System," Int. Symp. Electromagn. Compat. - EMC Eur., pp. 434-439, 2016.

[24] J.-H. Seo, S.-M. Kim, and H.-K. Jung, "Rotor-Design Strategy of IPMSM for $42 \mathrm{~V}$ Integrated Starter Generator," IEEE Trans. Magn., vol. 46, no. 6, pp. 2458-2461, Jun. 2010.

[25] L. Chédot, G. Friedrich, J. Biedinger, and P. Macret, "Integrated Starter Generator: The Need for an Optimal Design and Control Approach .
Application to a Permanent Magnet Machine," IEEE Trans. Ind. Appl., vol. 43 , no. 2 , pp. 551-559, 2007.

[26] G. Friedrich and A. Girardin, "Integrated starter generator," IEEE Ind. Appl. Mag., vol. 15, no. 4, pp. 26-34, 2009.

[27] G. Lo Calzo, P. Zanchetta, C. Gerada, A. Gaeta, and F. Crescimbini, "Converter Topologies comparison for more electric aircrafts high speed Starter / Generator application," IEEE Energy Convers. Congr. Expo., pp. 3659-3666, 2015.

[28] K. Muehlbauer and D. Gerling, "Two-Generator-Concepts for Electric Power Generation in More Electric Aircraft Engine," Int. Conf. Electr. Mach., 2010.

[29] S. Pugliese, R. A. Mastromauro, and S. Stasi, "270V / 28V Wide Bandgap Device-Based DAB Converter for More-Electric-Aircrafts : feasibility and optimization," Electr. Syst. Aircraft, Railw. Sh. Propuls., 2016.

[30] D. Izquierdo, R. Azcona, F. J. L. del Cerro, C. Fernández, and B. Delicado, "Electrical Power Distribution System ( HV270DC ), for Application in More Electric Aircraft," IEEE Appl. Power Electron. Conf. Expo., no. 1, pp. 1300-1305, 2010.

[31] G. Chen, Y.-S. Lee, S. Y. R. Hui, D. Xu, and Y. Wang, "Actively clamped bidirectional flyback converter," IEEE Transactions on Industrial Electronics, vol. 47, no. 4. pp. 770-779, 2000.

[32] M. Cacciato, F. Caricchi, F. Giuhlii, and E. Santini, "A critical evaluation and design of bi-directional DC/DC converters for super-capacitors interfacing in fuel cell applications," Conference Record of the 2004 IEEE Industry Applications Conference, 2004. 39th IAS Annual Meeting., vol. 2. pp. 1127-1133 vol.2, 2004.

[33] F. Zhang, L. Xiao, and Y. Yan, "Bi-directional forward-flyback DC-DC converter," 2004 IEEE 35th Annual Power Electronics Specialists Conference (IEEE Cat. No.04CH37551), vol. 5. p. 4058-4061 Vol.5, 2004.

[34] S. M. S. I. Shakib and S. Mekhilef, "A Frequency Adaptive Phase Shift Modulation Control Based LLC Series Resonant Converter for Wide Input Voltage Applications," IEEE Transactions on Power Electronics, vol. 32, no. 11. pp. 8360-8370, 2017.

[35] Z. Li and $\mathrm{H}$. Wang, "Comparative analysis of high step-down ratio isolated DC/DC topologies in PEV applications," 2016 IEEE Applied Power Electronics Conference and Exposition (APEC). pp. 1329-1335, 2016.

[36] J. Walter and R. W. De Doncker, "High-power galvanically isolated DC/DC converter topology for future automobiles," Power Electronics Specialist Conference, 2003. PESC '03. 2003 IEEE 34th Annual, vol. 1. pp. 27-32 vol.1, 2003.

[37] A. R. Alonso, J. Sebastian, D. G. Lamar, M. M. Hernando, and A. Vazquez, "An overall study of a Dual Active Bridge for bidirectional DC/DC conversion," 2010 IEEE Energy Conversion Congress and Exposition. pp. 1129-1135, 2010.

[38] R. De Doncker, D. M. Divan, and M. H. Kheraluwala, "A three-phase soft-switched high-power-density DC/DC converter for high-power applications," IEEE Trans. Ind. Appl., vol. 27, no. 1, pp. 63-73, 1991.

[39] G. Spiazzi and S. Buso, "Analysis of the Interleaved Isolated Boost Converter with Coupled Inductors," IEEE Trans. Ind. Electron., vol. 62, no. 7, pp. 4481-4491, 2014.

[40] M. H. Kheraluwala, R. W. Gascoigne, D. M. Divan, and E. D. Baumann, "Performance characterization of a high-power dual active bridge DC-toDC converter," IEEE Trans. Ind. Appl., vol. 28, no. 6, pp. 1294-1301, 1992.

[41] F. Krismer and J. W. Kolar, "Accurate Small-Signal Model for the Digital Control of an Automotive Bidirectional Dual Active Bridge," IEEE Trans. Power Electron., vol. 24, no. 12, pp. 2756-2768, 2009.

[42] H. Bai, C. C. Mi, and S. Gargies, "The Short-Time-Scale Transient Processes in High-Voltage and High-Power Isolated Bidirectional DC\&\#x2013;DC Converters," IEEE Transactions on Power Electronics, vol. 23, no. 6. pp. 2648-2656, 2008. 